\title{
Intake of non-nutritive sweeteners is associated with an unhealthy lifestyle: a cross-sectional study in subjects with morbid obesity
}

\author{
Robert Winther ${ }^{1,2}$, Martin Aasbrenn ${ }^{3,4}$ and Per G. Farup ${ }^{1,4^{*}}$ (D)
}

\begin{abstract}
Background: Subjects with morbid obesity commonly use Non-Nutritive Sweeteners (NNS), but the health-related effects of NNS have been questioned. The objectives of this study were to explore the associations between theuse of NNS and the health and lifestyle in subjects with morbid obesity.

Methods: This cross-sectional study included subjects with morbid obesity (BMl $\geq 40 \mathrm{~kg} / \mathrm{m}^{2}$ or $\geq 35 \mathrm{~kg} / \mathrm{m}^{2}$ with obesity-related comorbidity). Information about demographics, physical and mental health, and dietary habits was collected, and a blood screen was taken. One unit of NNS was defined as $100 \mathrm{ml}$ beverages with NNS or 2 tablets/ units of NNS for coffee or tea. The associations between the intake of NNS and the health-related variables were analyzed with ordinal regression analyses adjusted for age, gender and BMI.

Results: One hundred subjects (women/men 83/17; mean age 44.3 years (SD 8.5)) were included. Median intake of NNS was 3.3 units (range $0-43$ ). Intake of NNS was not associated with BMI $(p=0.64)$. The intake of NNS was associated with reduced heavy physical activity $(p=0.011)$, fatigue $(p<0.001)$, diarrhea $(p=0.009)$ and reduced well-being $(p=0.046)$; with increased intake of total energy $(p=0.003)$, fat $(p=0.013)$, carbohydrates $(p=0.002)$, sugar $(p=0.003)$ and salt $(p=0.001)$; and with reduced intake of the vitamins $\mathrm{A}(p=0.001), C(p=0.002)$ and $\mathrm{D}$ $(p=0.016)$.

Conclusions: The use of NNS-containing beverages was associated with an unhealthy lifestyle, reduced physical and mental health and unfavourable dietary habits with increased energy intake including sugar, and reduced intake of some vitamins.
\end{abstract}

Keywords: Diet, General health, Life style, Non-nutritive sweeteners, Obesity

\section{Background}

In adults, the global prevalence rates of overweight and obesity, defined as Body Mass Index (BMI) above 25 and $30 \mathrm{~kg} / \mathrm{m}^{2}$, were in $201439 \%$ and $13 \%$ respectively [1]. The prevalence rates have more than doubled since 1980 and the disorders have been mentioned as one of the largest public health concerns worldwide because of the increased

\footnotetext{
* Correspondence: per.farup@ntnu.no

'Department of Research, Innlandet Hospital Trust, PB 104, N-2381 Brumunddal, Norway

${ }^{4}$ Unit for Applied Clinical Research, Department of Clinical and Molecular Medicine, Faculty of Medicine and Health Sciences, Norwegian University of Science and Technology, N-7491 Trondheim, Norway

Full list of author information is available at the end of the article
}

risk of serious non-communicable diseases such as cancer, cardiovascular diseases, and diabetes [1-3]. In Norway, 1 in 4 middle-aged men and 1 in 5 women have a BMI above $30 \mathrm{~kg} / \mathrm{m}^{2}$ [4].

The "obesity epidemic" (the rapidly increasing prevalence) is caused by environmental and societal changes with increased intake of energy-dense food and increased physical inactivity [1]. Interventions at the societal level should facilitate regular physical activity and make healthier dietary choices available [1]. At the individual level, it is recommended to limit the energy intake from fat and sugar, to increase the intake of fruits, 
vegetables, legumes, whole grains and nuts, and to increase the regular physical activity [1].

To maintain the pleasure of the sweet taste and at the same time reduce the energy intake, subjects with obesity commonly replace sugar by non-nutritive sweeteners (NNS). The reasoning is logical and the producers of NNS have promoted the use and raised the global market to $\$ 5.5$ billion in 2014 [5]. The effect of NNS on weight prevention and reduction is controversial, and serious safety concerns have been raised [6-11]. The controversies are in part related to the study design. Observational studies indicate weight gain and interventional studies the opposite [12]. Both designs are prone to bias. Bias is also introduced by the industry; the relative risk to have favourable results in industry-sponsored reviews was 17.25 (95\%CI 2.34 to 127.29$)$ times that of industry independent ones [2]. Most studies have focused on the effect on body weight, whereas associations with lifestyle and general health have been less studied.

The aims of this study in subjects with morbid obesity were to assess associations between the use of NNS and demographics, lifestyle, physical and mental health, dietary habits, comorbidity and a blood screen.

\section{Methods}

\section{Study design}

This cross-sectional study was performed at the unit for morbid obesity at Innlandet Hospital Trust, Gjøvik, Norway. Consecutive subjects were included from December 2012 through September 2014. A medical history was taken, a physical examination was performed, and a blood sample was collected for further analyses. The patients filled in paper-based questionnaires. A trained study nurse was responsible for the care of the patients and the practical work.

\section{Subjects}

Consecutive subjects aged 18 - 65 years old with a BMI $\geq 40 \mathrm{~kg} / \mathrm{m}^{2}$ or $\geq 35 \mathrm{~kg} / \mathrm{m}^{2}$ with obesity-related complications referred for evaluation of bariatric surgery or conservative treatment were included in a comprehensive study. Subjects with serious somatic and psychiatric disorders judged as unrelated to obesity and subjects with previous major surgery including bariatric surgery were excluded. Only subjects with satisfactorily filled in food frequency questionnaires (FFQ) were included in this study.

\section{Variables}

Demographics: Gender; age (years); body weight $(\mathrm{kg})$, height (meter), body mass index (BMI, $\left.\mathrm{kg} / \mathrm{m}^{2}\right)$; cohabitant (yes/no); working (no / part-time / full-time); smoking (never / previously / daily); and overall physical activity (score $0-8$ ) and heavy physical activity (hours per week: no / <1 / 1-2 / >2).

Diseases, disorders and well-being: Perceived state of health (poor / not quite good / good / very good); present or previous somatic disorders including hypertension, diabetes, and fibromyalgia (yes / no); muscle-skeletal pain score (score 0-12); WHO-5 well-being index (score 0-100; score $\leq 28=$ likely depression; $\quad$ score $\leq 50=$ low mood); Hopkins Symptom Checklist -10 (HSCL-10) for measurement of mental distress (score 1-4; mental distress $\geq 1,85$ ); Fatigue severity scale (FSS; score 9-63, score $\geq 36$ = fatigue) [13-15]. The functional gastrointestinal disorders Irritable bowel Syndrome (IBS), functional constipation, functional diarrhea, and functional bloating were diagnosed with a validated Norwegian translation of the Rome III criteria; and the degree of gastrointestinal complaints with Gastrointestinal Symptom Rating Scale - IBS (GSRS-IBS) with subscales for GSRS-diarrhea, -constipation and -bloating (scores 1-7) [16, 17].

The dietary intake of nutrients, energy, and NNS was assessed with an FFQ prepared and validated by the Department of Nutrition at the University of Oslo, Norway who also analyzed the FFQs with their in-house calculation program (KBS, version 7.3, food database AE-14) based on the official Norwegian food composition table from 2016 (http://www.matvaretabellen.no). The frequency was reported as less than once/week; 1-2 times/ week; 3-4 times/week; 5-6 times/week; once daily; 2 times/day; 3 times/day; $\geq 4$ times/day. The portion size was reported in liter $(1 / 5,1 / 3: 1 / 2,1)$ and/or glasses and the amounts converted into gram/day. As the FFQ did not capture the type or amount of NNS used in beverages or NNS tablets, the calculation of the NNS intake was performed pragmatically. One unit of NNS was defined as $100 \mathrm{ml}$ NNS-containing beverage (divided into carbonated and non-carbonated beverage). This was considered as the amount of NNS that would equal the sweetening of regular sugar containing beverages with $10 \%$ of sugar $(10 \mathrm{~g} / 100 \mathrm{ml})$. One tablet of NNS was approximately equal to 1 teaspoon of sugar $(5 \mathrm{~g})$. Thus, 2 NNS tablets/units for use in tea or coffee were judged as equally amount of $100 \mathrm{ml}$ NNS in beverages. $100 \mathrm{ml}$ was chosen as the unit because the subjects reported the intake in liter and/or glasses and the unit is easy to understand. Intakes of NNS from other sources than beverages and tablets used in beverages were not included in the FFQ. Sugar alcohols and naturally-derived sweeteners not defined as NNS were not included. A range of hematological and biochemical blood tests including vitamins and minerals were analyzed.

\section{Statistics}

The results have been reported as mean (SD), median (range), and number (proportion in percentage). Because 
the intake of NNS varied markedly and was clustered in groups, the intake was ordered in groups with roughly uniform intake and analyzed with ordinal regression analyses. Associations between NNS and the subjects' characteristics and blood tests were analyzed with ordinal logistic regression analyses adjusted for age, gender and BMI and reported as B- and $p$-values. The associations between NNS and dietary intake were not linear and were analyzed with Spearman's correlation test reported as rho, and the p-values were calculated with ordinal logistic fractional polynomial regression adjusted for gender, age and BMI. The analyses were performed with IBM SPSS Statistics for Windows, Version 24.0. Armonk, NY: IBM Corp, and the fractional polynomial regression analyses with STATA v14, StatCorp LLC, Texas, USA. $P$-values $<0.05$ were judged as statistically significant.

\section{Ethics}

The study was approved by the Norwegian Regional Committees for Medical and Health Research Ethics, PB 1130, Blindern, 0318 Oslo, Norway (reference number 2012/966) and performed in accordance with the Declaration of Helsinki. Written informed consent to participate was given by all participants before inclusion.

\section{Results}

Out of 350 consecutive subjects visiting the obesity unit, 100 (83 women and 17 men with a mean age of 44.3 years (SD 8.5)) were included in the study. The reasons for the exclusion of 250 subjects are given in Fig. 1. Table 1 gives the participants' characteristics in detail and the results of the blood tests. Table 2 gives the daily dietary intake of energy, energy-yielding nutrients, NNS, vitamins, and salt. The total intake of NNS varied from zero to 43 units per day. High intake of NNS was associated with diabetes, reduced physical activity, fatigue, reduced well-being, and diarrhea (Table 3). Table 4 gives all the associations between intake of NNS and the dietary intake of energy, energy-yielding nutrients, vitamins, and salt. Intake of NNS was associated with increased intake of energy and salt, and reduced intake of vitamins. The positive associations between the intake of NNS and energy and salt were most pronounced for the use of NNS in carbonated beverages and are presented in Fig. 2.

\section{Discussion}

The study confirms the findings from studies in the general population that the use of NNS is high in overweight and obese adults [18-21]. Half of the subjects used more than 3.3 units of NNS per day, which corresponds to $330 \mathrm{ml}$ beverages with NNS. An intake of $2-41$ was not uncommon.

The main finding was the associations between NNS and an unhealthy lifestyle. In literature, less is known about these clinically relevant outcomes than about the weight. In this study, NNS was associated with a less healthy diet, reduced physical activity, low well-being and fatigue, which indicate an unhealthy lifestyle. The results indicate that the intake of NNS-containing beverages was approximately $100 \mathrm{ml}$ higher in subjects with diabetes than in those without, and the same difference was seen between those with strong physical activity less than 1 hour/week compared to those with more than 2 $\mathrm{h}$, and in subjects with low mood. The clinical significance of these effects are uncertain, but is indicative of an unhealthy lifestyle associated with the use of NNS.

A high intake of NNS was associated with increased intake of fat, proteins, carbohydrates including sugar,

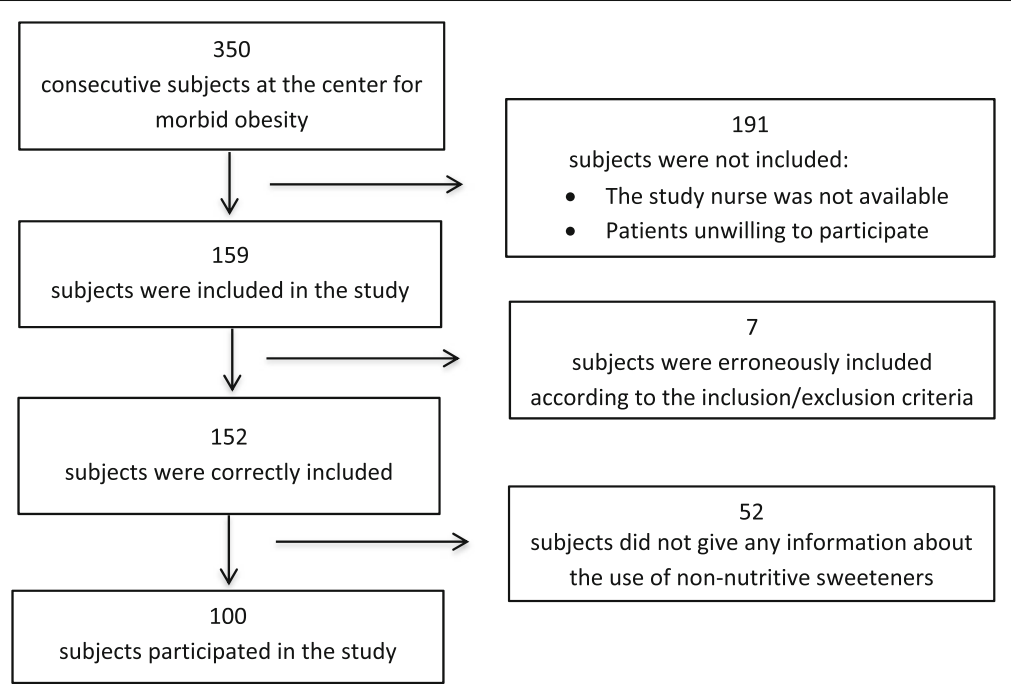

Fig. 1 A flow chart of the subjects in the study 
Table 1 The characteristics of the participants in the study

\begin{tabular}{|c|c|c|}
\hline $\begin{array}{l}\text { Participants' characteristics } \\
\text { (if less than } 100 \text {, the number is given in brackets) }\end{array}$ & $\begin{array}{l}\text { Mean } \\
\text { Median } \\
\text { Number }\end{array}$ & $\begin{array}{l}\text { SD } \\
\text { Range } \\
\text { Proportion } \\
(\%)\end{array}$ \\
\hline Gender (female/male) & $83 / 17$ & $83 \% / 17 \%$ \\
\hline Age (years) & 44.3 & 8.5 \\
\hline Body weight (kg) & 121.8 & 16.2 \\
\hline $\mathrm{BMI}(\mathrm{kg} / \mathrm{m} 2)$ & 41.9 & 3.5 \\
\hline Living with someone (99) & 84 & $85 \%$ \\
\hline Working (no / part time / full-time) (98) & $\begin{array}{l}23 / 32 / \\
43\end{array}$ & $23 \% / 33 \% / 44 \%$ \\
\hline Smoking (never/previously/daily) & $\begin{array}{l}43 / 44 / \\
13\end{array}$ & $43 \% / 44 \% / 13 \%$ \\
\hline Total physical activity (score 0-8) & 4.6 & 2.2 \\
\hline $\begin{array}{l}\text { Heavy physical activity (hrs. Per week: no / <1 / 1- } \\
2 />2 \text { ) }\end{array}$ & $\begin{array}{l}28 / 29 / 32 / \\
11\end{array}$ & $\begin{array}{l}28 \% / 29 \% / 32 \% / \\
11 \%\end{array}$ \\
\hline $\begin{array}{l}\text { State of health (98) (Poor/Not quite good/ Good/ } \\
\text { Very good) }\end{array}$ & $\begin{array}{l}10 / 54 / 30 / \\
4\end{array}$ & $\begin{array}{l}10 \% / 55 \% / 31 \% / \\
4 \%\end{array}$ \\
\hline Fibromyalgia & 19 & $19 \%$ \\
\hline Muscle-skeletal pain score (range 0-12) & 4.0 & $0-12$ \\
\hline Hypertension (96) & 57 & $59 \%$ \\
\hline Diabetes & 20 & $20 \%$ \\
\hline HSCL10 > 1.85 (mental distress) & 27 & $27 \%$ \\
\hline WHO-5 (low mood) (cut-off <50) & 30 & $30 \%$ \\
\hline Fatigue (cut-of >36) (99) & 48 & $48 \%$ \\
\hline Irritable bowel syndrome (97) & 27 & $28 \%$ \\
\hline Functional bloating (96) & 14 & $15 \%$ \\
\hline Functional diarrhea (97) & 2 & $2 \%$ \\
\hline GSRS-diarrhea (score 1 - 7) (80) & 1.5 & $1.0-4.8$ \\
\hline GSRS-bloating (score 1 - 7) (80) & 2.3 & $1.0-6.0$ \\
\hline \multicolumn{3}{|l|}{ Blood tests } \\
\hline Haemoglobin (F: 11-15; M: 13-17 g/dl) (98) & 14.4 & 1.1 \\
\hline Serum iron $(9-34$ umol/L (98) & 15.0 & 5.5 \\
\hline Transferrin saturation (0.10-0.57) (97) & 0.23 & 0.09 \\
\hline Ferritin $(10-380 \mu \mathrm{g} / \mathrm{dL})(98)$ & 96 & $7-584$ \\
\hline CRP (<5 mg/L) (98) & 5 & $0-28$ \\
\hline $\mathrm{s}$-Glucose (4.2-6.3 mmol/L) (98) & 5.7 & $4.0-23.2$ \\
\hline $\mathrm{HbA1C}(4.3-5.6 \%)(98)$ & 5.4 & $4.6-11.5$ \\
\hline C-peptide (0.3-2.4 nmol/L) (98) & 1.47 & $0.53-4.31$ \\
\hline Cholesterol (3-7 mmol/L) (98) & 5.0 & 1.0 \\
\hline HDL (F: 1.0-2.7; M: 0.8-2.1 mmol/L) (98) & 1.2 & 0.3 \\
\hline LDL (1-5 mmol/L) (98) & 3.3 & 0.9 \\
\hline Vitamin A (1.2-3.4 $\mu \mathrm{mol} / \mathrm{L})(91)$ & 2.0 & 0.4 \\
\hline Vitamin B1 (122-223 nmol/l) (97) & 158 & 27 \\
\hline Vitamin B6 (27-273 nmol/I) (96) & 23 & $6-209$ \\
\hline Vitamin B12 (141-700 pmol/L) (98) & 338 & $173-1401$ \\
\hline Vitamin D (45-161 nmol/L) (98) & 58 & 23 \\
\hline Folic acid (9-36 nmol/l) & 17 & $7-46$ \\
\hline
\end{tabular}

HSCL10 Hopkins Symptom Checklist 10, WHO-5 WHO-5 Well-Being Index, GSRS Gastrointestinal Symptom Rating Scale, HDL High Density Lipoprotein, LDL Low Density Lipoprotein
Table 2 Daily intake of total energy, energy-yielding nutrients, non-nutritive sweeteners, vitamins and salt

\begin{tabular}{|c|c|c|}
\hline Daily dietary intake & Median & Range \\
\hline \multicolumn{3}{|l|}{ Energy } \\
\hline Total energy (kJ) & 9737 & $2648-21,816$ \\
\hline Protein (g) & 109 & $40-212$ \\
\hline Fat (g) & 90 & $21-283$ \\
\hline Carbohydrates (g) & 251 & $65-903$ \\
\hline Sugar (g) & 26 & $1-632$ \\
\hline \multicolumn{3}{|l|}{ Non-nutritive sweeteners (NNS) (unit ${ }^{\mathrm{a}}$ ) } \\
\hline NNS total & 3.3 & $0.0-43.0$ \\
\hline NNS carbonated beverages & 0.4 & $0.0-40.0$ \\
\hline NNS non-carbonated beverages & 0.1 & $0.0-32.0$ \\
\hline NNS sweeteners in coffee and tea & 0.0 & $0.0-27.0$ \\
\hline \multicolumn{3}{|l|}{ Vitamins and salt } \\
\hline Vitamin A $(\mu \mathrm{g})$ & 1341 & $352-4460$ \\
\hline Vitamin B1 (mg) & 2.6 & $0.8-7.8$ \\
\hline Vitamin B2 (mg) & 3.0 & $1.1-8.8$ \\
\hline Vitamin B6 (mg) & 2.7 & $0.9-10.0$ \\
\hline Vitamin B12 $(\mu \mathrm{g})$ & 9.3 & $3.0-33.7$ \\
\hline Vitamin C (mg) & 170 & $11-623$ \\
\hline Vitamin D $(\mu \mathrm{g})$ & 12.5 & $2.2-44.6$ \\
\hline Folic acid $(\mu \mathrm{g})$ & 391 & $131-1077$ \\
\hline$\beta$-carotene $(\mu \mathrm{g})$ & 4947 & $340-24,306$ \\
\hline Salt (g) & 7.5 & $2.4-18.8$ \\
\hline
\end{tabular}

${ }^{\text {a }}$ NNS One unit $=100 \mathrm{ml}$ beverages with NNS or 2 units of NNS for coffee/ tea

and salt; and reduced intake of some vitamins. The high intake of energy is harmful to obese subjects. The association with the intake of sugar could support the hypothesis that NNS encourage sugar craving and dependence by an altered metabolism and processing of sweet taste in the brain $[22,23]$. Most of the unfavorable associations were related to the use of NNS in carbonated beverages, probably because the highest intake of NNS was from carbonated beverages. The stongest correlations were between intake of NNS containing beverages and salt. It is likely that these users combine the beverages with intake of salted food and snacks, which has also been shown by others [18]. Most of the associations between intake of NNS and energy and nutrients were weak (rho <0.2) and NNS explain only a minor part of the variation. The negative associations between intake of NNS and c-peptid, HbA1c and perhaps also $\mathrm{Hb}$ might have been confounded by diabetes. To adjust the analyses for all comorbidity including diabetes, in addition to age, gender and BMI was judged as inappropriate. The users of NNS in non-carbonated beverages, tea, and coffee seem to have a more conscious and correct use of NNS with a slightly reduced intake of total energy, 
Table 3 Associations between non-nutritive sweeteners (dependent variable) and subjects' characteristics

\begin{tabular}{|c|c|c|c|c|c|c|c|c|}
\hline \multirow[t]{2}{*}{ Patient characteristics } & \multicolumn{2}{|l|}{$\begin{array}{l}\text { NNS } \\
\text { total }\end{array}$} & \multicolumn{2}{|c|}{$\begin{array}{l}\text { NNS carb. } \\
\text { beverages }\end{array}$} & \multicolumn{2}{|c|}{$\begin{array}{l}\text { NNS non-carb. } \\
\text { beverages }\end{array}$} & \multicolumn{2}{|c|}{$\begin{array}{l}\text { NNS } \\
\text { sweeteners }\end{array}$} \\
\hline & $\bar{B}$ & $\overline{p \text {-value }}$ & $B$ & $\overline{p \text {-value }}$ & $B$ & $\overline{p \text {-value }}$ & $B$ & $\overline{p \text {-value }}$ \\
\hline Gender (female/male) & -0.10 & 0.838 & 0.519 & 0.285 & -0.049 & 0.924 & -2.896 & 0.005 \\
\hline Age (years) & -0.04 & 0.073 & -0.014 & 0.544 & -0.045 & 0.063 & 0.002 & 0.951 \\
\hline BMI (kg/m2) & -0.025 & 0.640 & -0.007 & 0.902 & -0.032 & 0.582 & 0.040 & 0.510 \\
\hline Living with someone & -0.728 & 0.151 & -0.030 & 0.953 & -0.981 & 0.060 & -0.011 & 0.985 \\
\hline Working & -0.124 & 0.594 & 0.383 & 0.114 & -0.379 & 0.126 & -0.047 & 0.858 \\
\hline Smoking & 0.194 & 0.485 & 0.196 & 0.492 & -0.043 & 0.884 & -0.110 & 0.715 \\
\hline Perceived general health & 0.011 & 0.965 & 0.070 & 0.793 & 0.098 & 0.722 & 0.083 & 0.771 \\
\hline Total physical activity & -0.184 & 0.029 & -0.086 & 0.308 & -0.030 & 0.732 & 0.014 & 0.883 \\
\hline Heavy physical activity & -0.477 & 0.011 & -0.368 & 0.052 & -0.212 & 0.278 & 0.116 & 0.576 \\
\hline Hypertension & 0.201 & 0.607 & 0.261 & 0.518 & -0.128 & 0.759 & -0.340 & 0.442 \\
\hline Diabetes & 0.971 & 0.039 & 0.639 & 0.174 & 1.227 & 0.012 & 0.171 & 0.748 \\
\hline Fibromyalgia & 0.696 & 0.131 & 0.202 & 0.664 & 0.718 & 0.132 & 0.568 & 0.249 \\
\hline Muscle-skeletal pain score (range 0-12) & -0.004 & 0.952 & 0.001 & 0.987 & -0.097 & 0.149 & 0.058 & 0.397 \\
\hline HSCL10 > 1.85 & 0.073 & 0.855 & -0.194 & 0.639 & -0.664 & 0.137 & -0.028 & 0.951 \\
\hline WHO-5 (poor wellbeing) & 0.452 & 0.249 & 0.805 & 0.046 & -0.135 & 0.746 & -0.297 & 0.509 \\
\hline Fatigue & 1.232 & 0.001 & 0.490 & 0.184 & 0.316 & 0.408 & 0.575 & 0.159 \\
\hline IBS & 0.317 & 0.444 & -0.193 & 0.651 & 0.207 & 0.633 & -0.047 & 0.915 \\
\hline Functional bloating & -0.379 & 0.486 & 0.600 & 0.280 & -0.714 & 0.258 & -1.365 & 0.067 \\
\hline Functional diarrhea & NA & NA & NA & NA & NA & NA & NA & NA \\
\hline GSRS-diarrhea (score) & 0.625 & 0.009 & 0.178 & 0.447 & 0.176 & 0.467 & 0.626 & 0.012 \\
\hline GSRS-bloating (score) & -0.112 & 0.509 & -0.033 & 0.849 & -0.324 & 0.084 & -0.184 & 0.320 \\
\hline \multicolumn{9}{|l|}{ Blood tests } \\
\hline Haemoglobin (g/dl) & -0.299 & 0.149 & -0.063 & 0.765 & -0.625 & 0.007 & -0.534 & 0.022 \\
\hline Serum iron $(\mu \mathrm{mol} / \mathrm{L}$ & -0.015 & 0.648 & -0.042 & 0.237 & -0.011 & 0.768 & -0.049 & 0.205 \\
\hline Transferrin saturation & -0.875 & 0.673 & -0.025 & 0.255 & -0.011 & 0.631 & -0.033 & 0.167 \\
\hline Ferritin ( $\mu \mathrm{g} / \mathrm{dL})$ & 0.002 & 0.311 & -0.001 & 0.450 & 0.000 & 0.909 & -0.001 & 0.615 \\
\hline CRP (mg/L) & 0.040 & 0.226 & 0.029 & 0.393 & 0.081 & 0.020 & 0.042 & 0.228 \\
\hline $\mathrm{s}-\mathrm{Glucose}(\mathrm{mmol} / \mathrm{L})$ & 0.110 & 0.082 & 0.122 & 0.055 & 0.044 & 0.492 & 0.005 & 0.944 \\
\hline $\mathrm{HbA1C}(\%)$ & 0.294 & 0.052 & 0.235 & 0.117 & 0.367 & 0.018 & 0.076 & 0.644 \\
\hline c-peptide (nmol/L) & 0.662 & 0.005 & 0.410 & 0.077 & 0.279 & 0.244 & 0.509 & 0.052 \\
\hline Cholesterol (mmol/L) & 0.116 & 0.542 & 0.188 & 0.339 & -0.043 & 0.830 & -0.096 & 0.661 \\
\hline $\mathrm{HDL}(\mathrm{mmol} / \mathrm{L})$ & -0.612 & 0.291 & -0.164 & 0.782 & -1.017 & 0.115 & 0.541 & 0.394 \\
\hline LDL (mmol/L) & 0.164 & 0.427 & 0.164 & 0.438 & -0.026 & 0.907 & -0.179 & 0.457 \\
\hline Vitamin A ( $\mu \mathrm{mol} / \mathrm{L})$ & 0.291 & 0.536 & -0.725 & 0.136 & -0.232 & 0.644 & 0.050 & 0.921 \\
\hline Vitamin B1 (nmol/L) & 0.008 & 0.243 & 0.006 & 0.356 & 0.001 & 0.876 & 0.007 & 0.363 \\
\hline Vitamin B6 (nmol/L) & 0.004 & 0.479 & 0.005 & 0.407 & -0.011 & 0.178 & -0.002 & 0.759 \\
\hline Vitamin B12 (pmol/L) & -0.001 & 0.384 & 0.000 & 0.727 & 0.000 & 0.940 & -0.001 & 0.503 \\
\hline Vitamin D (nmol/L) & 0.006 & 0.458 & 0.012 & 0.166 & 0.001 & 0.952 & 0.000 & 0.966 \\
\hline Folic acid (nmol/L) & -0.024 & 0.269 & -0.007 & 0.759 & -0.021 & 0.362 & -0.018 & 0.433 \\
\hline
\end{tabular}

HSCL10 Hopkins Symptom Checklist 10, WHO-5 WHO-5 Well-Being Index, IBS Irritable bowel syndrome, GSRS Gastrointestinal Symptom Rating Scale, HDL High Density Lipoprotein, LDL Low Density Lipoprotein

The analyses have been performed with ordinal logistic regression analyses adjusted for gender, age and BMI) 
Table 4 Associations between the intake of NNS and intake of energy, energy-yielding nutrients, vitamins and salt

\begin{tabular}{|c|c|c|c|c|c|c|c|c|}
\hline \multirow[t]{2}{*}{ Diet } & \multicolumn{2}{|c|}{ NNS Total } & \multicolumn{2}{|c|}{ NNS Carbonated } & \multicolumn{2}{|c|}{ NNS Non-carb } & \multicolumn{2}{|c|}{ NNS Sweeteners } \\
\hline & rho & $p$-value & rho & $p$-value & rho & $p$-value & rho & $p$-value \\
\hline Total energy (kcal) & 0.138 & 0.003 & 0.235 & 0.004 & -0.101 & 0.0329 & 0.014 & 0.080 \\
\hline Protein (g) & 0.081 & 0.106 & 0.198 & 0.012 & -0.066 & 0.551 & -0.007 & 0.028 \\
\hline Fat (g) & 0.172 & 0.013 & 0.273 & 0.005 & -0.053 & 0.043 & 0.083 & 0.094 \\
\hline Carbohydrates (g) & 0.145 & 0.002 & 0.221 & 0.014 & -0.097 & 0.031 & -0.048 & 0.031 \\
\hline Sugar (g) & 0.204 & 0.003 & 0.257 & 0.003 & -0.037 & 0.091 & -0.111 & 0.012 \\
\hline Vitamin A ( $\mu \mathrm{g})$ & -0.242 & 0.001 & -0.092 & 0.077 & -0.185 & 0.014 & -0.016 & 0.659 \\
\hline Vitamin B1 (mg) & -0.076 & 0.062 & -0.017 & 0.121 & -0.171 & 0.088 & 0.025 & 0.595 \\
\hline Vitamin B2 (mg) & -0.092 & 0.060 & -0.016 & 0.088 & -0.190 & 0.053 & 0.026 & 0.054 \\
\hline Vitamin B6 (mg) & -0.033 & 0.238 & -0.005 & 0.111 & -0.091 & 0.558 & 0.060 & 0.611 \\
\hline Vitamin B12 $(\mu \mathrm{g})$ & 0.027 & 0.804 & 0.103 & 0.584 & -0.017 & 0.622 & 0.066 & 0.595 \\
\hline Folic acid (mg) & -0.028 & 0.074 & 0.043 & 0.036 & -0.150 & 0.160 & 0.065 & 0.730 \\
\hline$\beta$-Carotene $(\mu \mathrm{g})$ & -0.154 & 0.091 & -0.084 & 0.145 & -0.175 & 0.033 & 0.107 & 0.428 \\
\hline Vitamin C (mg) & -0.194 & 0.002 & -0.050 & 0.051 & -0.172 & 0.026 & 0.084 & 0.083 \\
\hline Vitamin D $(\mu \mathrm{g})$ & -0.198 & 0.016 & -0.146 & 0.033 & -0.217 & 0.079 & -0.052 & 0.069 \\
\hline Salt (g) & 0.261 & 0.001 & 0.321 & $<0.001$ & 0.051 & 0.001 & 0.070 & 0.028 \\
\hline
\end{tabular}

NNS Non-Nutritive Sweeteneres

The correlations have been calculated with Spearmans' rho, and the p-values with ordinal logistic fractional polynomial regression adjusted for gender, age and BMI

carbohydrates, and sugar. They also reduced the intake of $\beta$-Carotene and vitamin $C$, indicating that they reduced all kinds of food including the healthy fruits and vegetables. Opposed to the findings in this study, population-based studies in the UK, US and Canada suggest a higher dietary quality in NNS consumers than in nonconsumers $[19,20]$. The way NNS are used and the physiological and psychological effect of NNS might differ between subjects randomly selected from the population and subjects referred for treatment of morbid obesity at a spesialised hospital unit. Although NNS have been accused of a diabetogenic effect, the associations between NNS and diabetes and c-peptide in this study are probably explained by the higher use of NNS by subjects with diabetes $[24,25]$.

Reduced physical and mental health was also associated with NNS. The users of NNS had a feeling of poor well-being and more fatigue, and were less physically
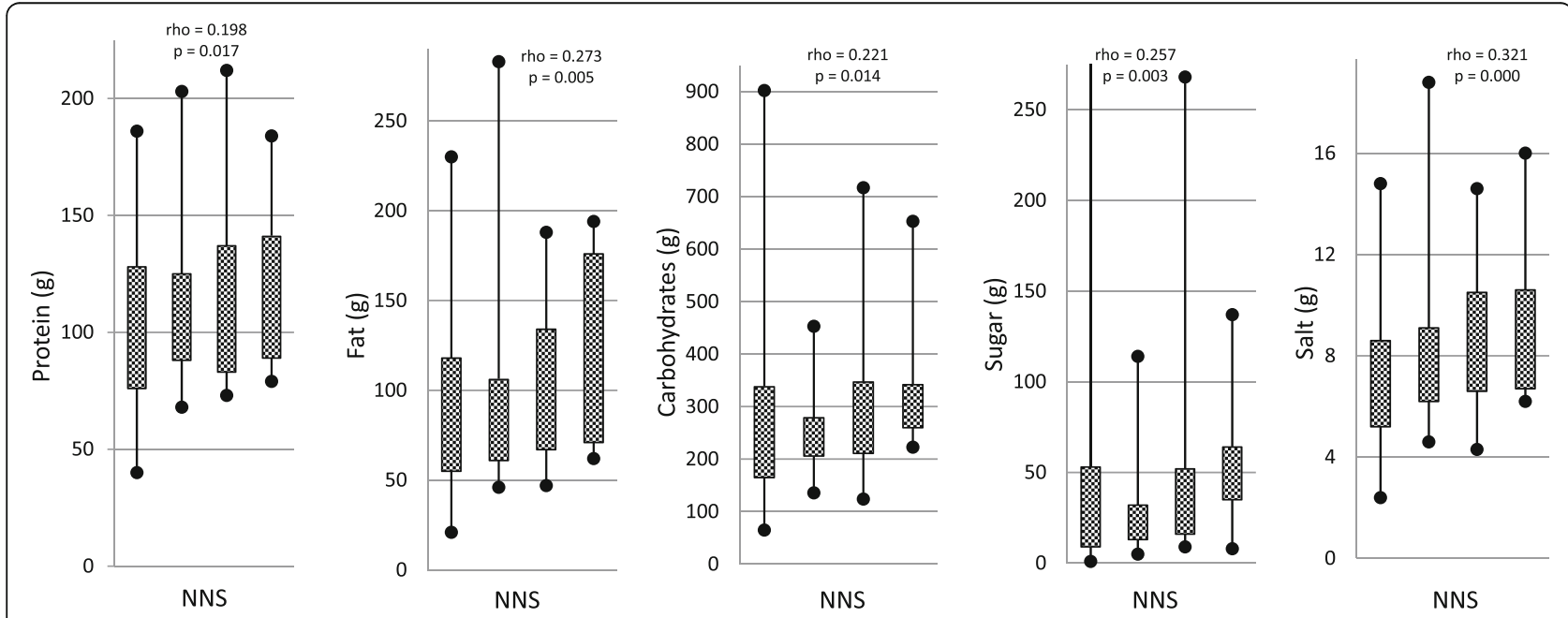

Fig. 2 Associations between the intake of NNS in carbonated beverages and intake of nutrients and salt. NNS: Non-Nutritive Sweeteners. The box-andwhisper plots indicate no (0 unit) /low (0.1 - 2.0 units) / medium ( 2.1 - 9.0 units) / high (9.0 - 40.0 units) intake of non-nutritive sweeteners in carbonated beverages. One unit $=100 \mathrm{ml}$ NNS-beverage/day. The correlations have been calculated with Spearmans' rho, and the $p$-values with ordinal logistic fractional polynomial regression. 
active. These aspects have not been focused on in literature as far as we know. Caffeine- and NNS-containing beverages might have been used to counteract fatigue and as an excuse for less physical activity. Diarrhea associated with NNS for use in coffee and tea might have been an adverse event related to some of the NNS.

The association between the use of NNS and BMI is not clear $[8,26]$. The lack of associations between the use of NNS and BMI in this study was likely because all subjects were morbidly obese, but could indicate a lack of weight-reducing effect of NNS. In population-based observational studies, the use of NNS is higher in overweight and obese subjects than in healthy-weight subjects [18-20]. The findings could indicate that NNS induce weight gain, but it more likely reflects the use of NNS for weight reduction by overweight and obese subjects.

Numerous studies from agriculture, in the laboratory and in humans indicate a counterintuitive effect of NNS with increased food intake and body weight, accumulation of fat, weaker caloric compensation, metabolic syndrome and cardiovascular diseases [27-29]. Animal studies have shown weight gain and metabolic dysregulation after intake of NNS [29, 30]. NNS are not inert substances, and physiological effects on metabolism and energy balance have been proposed to explain an unexpected weightinducing effect in long-term follow-up studies in children and adults [7, 31-33]. NNS affect the glucose metabolism and have been associated with type 2 diabetes [24, 34-36]. Concerns have also been raised about effects on appetite, eating behaviour, satiation, satiety, craving, reward, addiction, cognitive functions, neurophysiology, and brain function $[22,23,37-40]$.

More recently, the effect of NNS on the gut microbiome has achieved considerable attention. The disturbed gut-brain interaction caused by the NNS-induced dysbiosis might in part explain the effects associated with obesity such as weight gain, metabolic changes including glucose intolerance, neurophysiological and psychological changes [41-43].

Except for a slightly favourable effect in the subgroup of subjects using NNS-containing non-carbonated beverages, the overall findings were discouraging. It was anticipated that subjects who were referred for obesity and therefore motivated for weight-reducing interventions, had a conscious relation to the use of NNS as a way to reduce energy intake. Most of them had bariatric surgery later on.

Despite numerous concerns and an extensive literature, the correct use of NNS is unknown [25]. The actual knowledge has been summarized by the U.S. Department of Health and Human Services and U.S. Department of Agriculture in "Dietary Guidelines for Americans 2015-2020”: “... replacing added sugar with high-intensity sweeteners may reduce calorie intake in the short-term, yet questions remain about their effectiveness as a long-term weight management strategy", and "Based on available scientific evidence, these highintensity sweeteners have been determined to be safe for the general population" [44]. Shankar et al. gave an intelligent advice "...for optimal health it is recommended that only minimal amounts of both sugar and NNS be consumed" [45].

\section{Strengths and limitations}

The focus on an unselected group of consecutive subjects with morbid obesity from a general hospital and their health and lifestyle, and not on overweight and obesity in general and body weight only, was a strength. This study from a general hospital is likely to be representative of unselected consecutive subjects referred to a specialized unit for morbid obesity. The validity of the results for all subjects with overweight and obesity is unknown. The lack of information about the use of NNS in other products than beverages and the different types of NNS was a limitation. The FFQ only asked for the use of NNS-containing carbonated beverages, noncarbonated beverages and units of NNS in tea and coffee and not the specific products. Information about NNS in packets added to other beverages or food was not asked for. The limited sample size reduces the ability to control for confounders. No correction was performed for the numerous correlations, which increased the risk of type I errors.

\section{Conclusions}

The use of NNS-containing beverages in subjects with morbid obesity was associated with an unhealthy lifestyle, reduced physical and mental health, and unfavourable dietary habits. Lifestyle and dietary advice are therefore particularly important to subjects with morbid obesity using NNS-containing beverages. There were no significant associations between the use of NNScontaining beverages and BMI. The study gave no support for the recommendation of NNS-containing beverages to subjects with morbid obesity.

\section{Abbreviations \\ BMI: Body Mass Index; Cl: Confidence interval; FFQ: Food Frequency Questionnaire; GSRS: Gastrointestinal Symptom Rating Scale; HDL: High- Density Lipoprotein; HSCL-10: Hopkins Symptoms Checklist 10; IBS: Irritable Bowel Syndrome; LDL: Low-Density Lipoprotein; NNS: Non-Nutritive Sweeteners; SD: Standard Deviation; WHO: World Health Organization}

\section{Acknowledgements}

The authors want to thank Anne Stine Kvehaugen for the collection and scoring of the dietary data, Anja Byfuglien for conscientious help with the practical work and Innlandet Hospital Trust for the funding.

\section{Authors' contribution}

RW prepared the data file for the statistical analyses, performed parts of the statistical analyses and drafted the manuscript. MAa was responsible for the 
collection of the clinical data and prepared the data file for the statistical analyses together with RW. PGF is the guarantor of the project. He designed the main study, was responsible for the practical implementation, performed the statistical analyses, finalized the manuscript and is responsible for the integrity of the work. All authors have given valuable comments on the manuscript and approved the last version.

\section{Funding}

The work was supported by a grant from Innlandet Hospital Trust, Brumunddal, Norway.

Availability of data and materials.

Case report forms (CRFs) on paper were used for collection of the clinical data, and all the CRFs are safely stored. The data were transferred manually to SPSS for statistical analyses. The data files are stored by Innlandet Hospital Trust, Brumunddal, Norway, on a server dedicated to research and with security according to the rules given by The Norwegian Data Protection Authority, P.O. Box 8177 Dep. NO-0034 Oslo, Norway. The data are available on request to the authors.

\section{Ethics approval and consent to participate}

The study was approved by the Norwegian Regional Committees for Medical and Health Research Ethics, PB 1130, Blindern, 0318 Oslo, Norway (reference number 2012/966) and performed in accordance with the Declaration of Helsinki. Written informed consent was given by all participants before inclusion.

\section{Consent for publication}

Not applicable.

\section{Competing interests}

The authors declare that there are no conflicts of interest.

\section{Publisher's Note}

Springer Nature remains neutral with regard to jurisdictional claims in published maps and institutional affiliations.

\section{Author details}

'Department of Research, Innlandet Hospital Trust, PB 104, N-2381 Brumunddal, Norway. ${ }^{2}$ Faculty of Medicine, University of Aalborg, DK-9100 Aalborg, Denmark. ${ }^{3}$ Department of Surgery, Innlandet Hospital Trust, N-2819 Gjøvik, Norway. ${ }^{4}$ Unit for Applied Clinical Research, Department of Clinical and Molecular Medicine, Faculty of Medicine and Health Sciences, Norwegian University of Science and Technology, N-7491 Trondheim, Norway.

Received: 5 September 2017 Accepted: 11 December 2017

Published online: 27 December 2017

\section{References}

1. WHO Fact sheet N 311, Obesity and overweight. Updated June 2016. http:// www.who.int/mediacentre/factsheets/fs311/en/. Accessed 17 Nov 2017.

2. Mandrioli D, Kearns CE, Bero LA. Relationship between research outcomes and risk of bias, study sponsorship, and author financial conflicts of interest in reviews of the effects of artificially sweetened beverages on weight outcomes: a systematic review of reviews. PLoS One. 2016;11:e0162198.

3. Mitchell NS, Catenacci VA, Wyatt HR, Hill JO. Obesity: overview of an epidemic. Psychiatr Clin North Am. 2011;34:717-32.

4. Overweight and obesity in Norway. Norwegian Institute of Public Health https://www.fhi.no/en/op/public-health-report-2014/risk\%2D-protectivefactors/overweight-and-obesity-in-norway-\%2D-/. Accessed 18 Nov 2017.

5. Kumar A. Global Markets for non-Sugar Sweeteners. BCC Research LLC. https://www.bccresearch.com/market-research/food-and-beverage/nonsugar-sweeteners-global-markets-report-fod044b.html. Accessed $17 \mathrm{Nov}$ 2017

6. Fowler SP. Low-calorie sweetener use and energy balance: results from experimental studies in animals, and large-scale prospective studies in humans. Physiol Behav. 2016;164:517-23.

7. Chia CW, Shardell M, Tanaka T, Liu DD, Gravenstein KS, Simonsick EM, et al. Chronic low-calorie sweetener use and risk of abdominal obesity among older adults: a cohort study. PLoS One. 2016;11:e0167241.
8. Rogers PJ, Hogenkamp PS, de Graaf C, Higgs S, Lluch A, Ness AR, et al. Does low-energy sweetener consumption affect energy intake and body weight? A systematic review, including meta-analyses, of the evidence from human and animal studies. Int J Obes. 2016;40:381-94.

9. Peters JC, Beck J. Low calorie sweetener (LCS) use and energy balance. Physiol Behav. 2016;164:524-8.

10. Soffritti M, Padovani M, Tibaldi E, Falcioni L, Manservisi F, Belpoggi F. The carcinogenic effects of aspartame: the urgent need for regulatory reevaluation. Am J Ind Med. 2014;57:383-97.

11. Schernhammer ES, Bertrand KA, Birmann BM, Sampson L, Willett WC, Feskanich D. Consumption of artificial sweetener- and sugar-containing soda and risk of lymphoma and leukemia in men and women. Am J Clin Nutr. 2012;96:1419-28.

12. Roberts JR. The paradox of artificial sweeteners in managing obesity. Curr Gastroenterol Rep. 2015;17:423.

13. Strand BH, Dalgard OS, Tambs K, Rognerud M. Measuring the mental health status of the Norwegian population: a comparison of the instruments SCL25, SCL-10, SCL-5 and MHI-5 (SF-36). Nord J Psychiatry. 2003;57:113-8.

14. Topp CW, Ostergaard SD, Sondergaard S, Bech P. The WHO-5 well-being index: a systematic review of the literature. Psychother Psychosom. 2015;84: 167-76.

15. Whitehead $L$. The measurement of fatigue in chronic illness: a systematic review of unidimensional and multidimensional fatigue measures. J Pain Symptom Manag. 2009;37:107-28.

16. Longstreth GF, Thompson WG, Chey WD, Houghton LA, Mearin F, Spiller RC Functional bowel disorders. Gastroenterology. 2006;130:1480-91.

17. Wiklund IK, Fullerton S, Hawkey CJ, Jones RH, Longstreth GF, Mayer EA, et al. An irritable bowel syndrome-specific symptom questionnaire: development and validation. Scand J Gastroenterol. 2003;38:947-54.

18. Bleich SN, Wolfson JA, Vine S, Wang YC. Diet-beverage consumption and caloric intake among US adults, overall and by body weight. Am J Public Health. 2014;104:e72-8.

19. Drewnowski A, Rehm CD. Consumption of low-calorie sweeteners among U.S. adults is associated with higher healthy eating index (HEl 2005) scores and more physical activity. Nutrients. 2014;6:4389-403.

20. Gibson SA, Horgan GW, Francis LE, Gibson AA, Stephen AM. Low calorie beverage consumption is associated with energy and nutrient intakes and diet quality in British adults. Nutrients. 2016;8(1):9.

21. Bouchard DR, Ross R, Janssen I. Coffee, tea and their additives: association with BMI and waist circumference. Obes Facts. 2010;3:345-52.

22. Yang Q. Gain weight by "going diet?" artificial sweeteners and the neurobiology of sugar cravings: neuroscience 2010. Yale J Biol Med. 2010;83:101-8.

23. Green E, Murphy C. Altered processing of sweet taste in the brain of diet soda drinkers. Physiol Behav. 2012;107:560-7.

24. Imamura F, O'Connor L, Ye Z, Mursu J, Hayashino Y, Bhupathiraju SN, et al. Consumption of sugar sweetened beverages, artificially sweetened beverages, and fruit juice and incidence of type 2 diabetes: systematic review, meta-analysis, and estimation of population attributable fraction. $\mathrm{Br}$ J Sports Med. 2016:50:496-504.

25. Romo-Romo A, Aguilar-Salinas CA, Brito-Cordova GX, Gomez Diaz RA, Vilchis Valentin D, Almeda-Valdes P. Effects of the non-nutritive sweeteners on glucose metabolism and appetite regulating hormones: systematic review of observational prospective studies and clinical trials. PLoS One. 2016;11: e0161264

26. Peters JC, Wyatt HR, Foster GD, Pan Z, Wojtanowski AC, Vander Veur SS, et al. The effects of water and non-nutritive sweetened beverages on weight loss during a 12-week weight loss treatment program. Obesity (Silver Spring). 2014;22:1415-21.

27. Swithers SE, Martin AA, Davidson TL. High-intensity sweeteners and energy balance. Physiol Behav. 2010;100:55-62.

28. Swithers SE. Artificial sweeteners produce the counterintuitive effect of inducing metabolic derangements. Trends Endocrinol Metab. 2013;24:431-41.

29. Shearer J, Swithers SE. Artificial sweeteners and metabolic dysregulation: lessons learned from agriculture and the laboratory. Rev Endocr Metab Disord. 2016;17:179-86.

30. Swithers SE, Martin AA, Clark KM, Laboy AF, Davidson TL. Body weight gain in rats consuming sweetened liquids. Effects of caffeine and diet composition. Appetite. 2010;55:528-33.

31. Burke MV, Small DM. Physiological mechanisms by which non-nutritive sweeteners may impact body weight and metabolism. Physiol Behav. 2015; 152:381-8. 
32. Pepino MY. Metabolic effects of non-nutritive sweeteners. Physiol Behav. 2015;152:450-5.

33. Laverty AA, Magee L, Monteiro CA, Saxena S, Millett C. Sugar and artificially sweetened beverage consumption and adiposity changes: national longitudinal study. Int J Behav Nutr Phys Act. 2015;12:137.

34. Kuk JL, Brown RE. Aspartame intake is associated with greater glucose intolerance in individuals with obesity. Appl Physiol Nutr Metab. 2016;41: 795-8.

35. Gul SS, Hamilton AR, Munoz AR, Phupitakphol T, Liu W, Hyoju SK, et al. Inhibition of the gut enzyme intestinal alkaline phosphatase may explain how aspartame promotes glucose intolerance and obesity in mice. Appl Physiol Nutr Metab. 2017;42:77-83.

36. Sylvetsky AC, Brown RJ, Blau JE, Walter M, Rother Kl. Hormona responses to non-nutritive sweeteners in water and diet soda. Nutr Metab (Lond). 2016:13:71.

37. Hill SE, Prokosch ML, Morin A, Rodeheffer CD. The effect of non-caloric sweeteners on cognition, choice, and post-consumption satisfaction. Appetite. 2014;83:82-8.

38. Choudhary AK, Lee YY. Neurophysiological symptoms and aspartame: what is the connection? Nutr Neurosci. 2017;2017:1-11.

39. Rudenga KJ, Small DM. Amygdala response to sucrose consumption is inversely related to artificial sweetener use. Appetite. 2012;58:504-7.

40. Low YQ, Lacy K, Keast R. The role of sweet taste in satiation and satiety. Nutrients. 2014;6:3431-50.

41. Nettleton JE, Reimer RA, Shearer J. Reshaping the gut microbiota: impact of low calorie sweeteners and the link to insulin resistance? Physiol Behav. 2016;164:488-93.

42. Suez J, Korem T, Zilberman-Schapira G, Segal E, Elinav E. Non-caloric artificial sweeteners and the microbiome: findings and challenges. Gut Microbes. 2015;6:149-55.

43. Suez J, Korem T, Zeevi D, Zilberman-Schapira G, Thaiss CA, Maza O, et al. Artificial sweeteners induce glucose intolerance by altering the gut microbiota. Nature. 2014:514:181-6.

44. U.S. Dept of Health and Human Services and U.S. Dept of Agriculture. 2015 - 2020 Dietary Guidelines for Americans. 8th Edition.. https://health.gov/ dietaryguidelines/2015/guidelines/Accessed 18 Nov 2017.

45. Shankar P, Ahuja S, Sriram K. Non-nutritive sweeteners: review and update. Nutrition. 2013;29:1293-9.

\section{Submit your next manuscript to BioMed Central and we will help you at every step:}

- We accept pre-submission inquiries

- Our selector tool helps you to find the most relevant journal

- We provide round the clock customer support

- Convenient online submission

- Thorough peer review

- Inclusion in PubMed and all major indexing services

- Maximum visibility for your research

Submit your manuscript at www.biomedcentral.com/submit

Biomed Central 